\title{
STUDYED ON THE EXTERNALDEFECTS SEGMENTATION BASED ON THE COLOR CHARACTER OF POTATOES
}

\author{
Min $\mathrm{Hao}^{1}$, Shuoshi Ma ${ }^{1, *}$ \\ ${ }^{1}$ College of Electrical and Mechanical Engineering, Inner Mogolia Agriculture University, \\ Huhot,010018, China \\ * Corresponding author, Address: College of Electrical and Mechanical Engineering, Inner \\ Mogolia Agriculture University,Huhot,010018, Inner Mongolia Autonomous Region China \\ Tel:0471-4209285,Email:mashuoshi@imau.edu.cn
}

Abstract: Potato quality detection in China remains at the stage of dependent on human sense organ to identify and judge. According to the characteristics and requests of potatoes' detection, The original image was disposed fast and smoothly by the median filtering, and based on the threshold segmentation by setting up the values of $\mathrm{B}$ (blue), the background was effectively wiped off. By analyzing the circumscription of color characters between the normal and external defect potatoes, the external defect segmentation was realized. This way is simple and feasible.

Keywords: potatoes external defect; segmentation; color character

\section{INTRODUCTION}

Global awareness of the potato's key contribution to agriculture, the economy and world food security. The United Nations has declared 2008 as "International Year of the Potato", and potatoes was known as the "hidden treasures." Potatoes is a nutrient-rich agricultural products and is the world's number-four food crop after rice, wheat and maize, with annual production of more than 300 million tonnes in more than 100 countries. In China, potatoes is a major dominant crop in the Inner Mongolia Autonomous Region, potato yield is high. With the constant development and growing of

Please use the following format when citing this chapter:

Hao, M. and Ma, S., 2009, in IFIP International Federation for Information Processing, Volume 294, Computer and Computing Technologies in Agriculture II, Volume 2, eds. D. Li, Z. Chunjiang, (Boston: Springer), pp. 1175-1180. 
the potato processing enterprises, potato quality inspection and grading is a necessary topic that needs to be solved.

The way of agricultural products' quality detection, includes automatic and semi-automatic and nondestructive detection methods. When the growth potato affected by man-made and natural growth conditions and other complex factors, its shape, size, color, and other feature are different. While the existing potato classifier based on the classifying principle of only size detection, can not meet the requirements for the composite indicator detection. So in China, detections of potatoes are mainly depended on the human's sense organs, which lead to lowness of efficiency and bigness of error. In addition, such a subjective assessment depend on the individual ability, color resolution, fatigue and other conditions, can not meet the requirements of a high standard classification and go against automation.

Color is important in evaluating quality and maturity level of many agricultural products. Color grading is an essential step in the processing and inventory control of fruits and vegetables that directly affects profitability(Dah-Jye Lee et al.,2008). The researches were more in quality testing of seeds, rice, fruit, eggs, vegetables.etc(Ying Yibiin et al.,2005). But so far there has been little research on potatoes.

\section{TEST DEVICE AND RESEARCH OBJECT}

\subsection{Research Object}

Hohhot Wuchuan country is known as the "land of the Chinese Potato".Famous brand agricultural products "Wuchuan potato" had been selected special for the 2008 Beijing Olympic Games by Beijing Olympic Organizing Committee. Took image of variety KeXin 1 st potato from Hohhot Wuchuan country as the specific study object, make detection according to the standard of NY/T1066-2006 "Grades and specifications of potatoes".

\subsection{Hardware System}

The main function of the hardware system was data acquisition, transmission and processing. The hardware system included Basler A101fc face CCD camera made in Germany with high sensitivity and SNR (Signalto-noise Ratio);IEEE1394a image acquisition card; computer with AMD 2800 +, RAM 512M, hard drives 120G; 60W annularfluorescent lamp fixed on top of the light box(Fig 1). The image, an analog signal, which was 
exported from the camera and transformed into the digital signal by image acquisition card. The digital signal was storied in RAM for next processing .

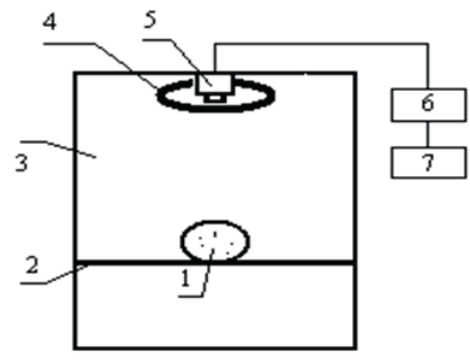
1potato sample
2 object stage
3 light bracket chamber
4 annular fluorescent lamp
5camera
Gimage acquisition card
7 computer

Fig. 1: Hardware system

\subsection{Software Technology}

Potato original image was 24 bit true color image, the image resolution was $1030 * 1300$. The processing was realized by using MATLAB 7.0.

\section{IMAGE PREPROCESSING}

The original image was disposed fast and smoothly by the linear low pass filtering. For the major color of the potato is yellow and the color yellow is compound of red and green, based on the threshold segmentation by setting up the values of B(blue), the background was effectively wiped off. Speckle noise was eliminated by the median filtering of $3 * 3$. The effect was obviously and was shown as Figure 2.

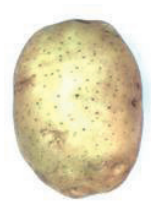

(a) high quality potato source inage

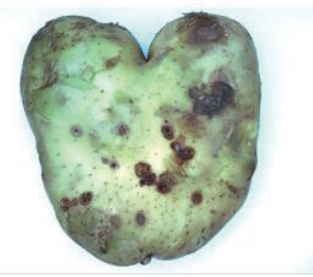

(d) external defects inage

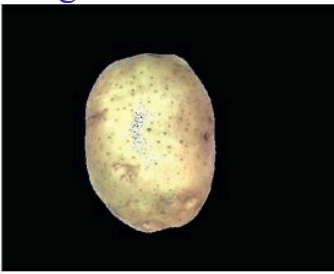

(b) golobal thresholding results of (a)

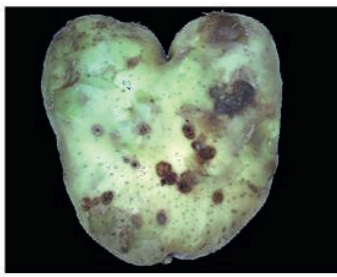

(e)golobal thresholding results of (d)

Fig.2: Image Preprocessing

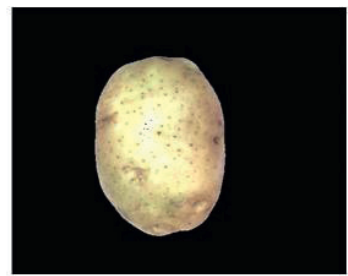

(c)nedian filtering results of (b)

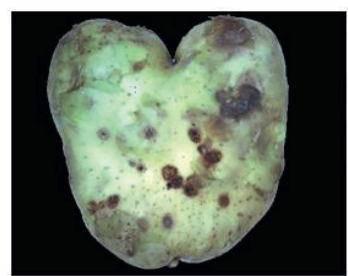

(f)nedian filter results of (e) 


\section{THE EXTERNAL DEFECT SEGMENTATION BASED ON THE COLOR CHARACTER OF POTATO}

Potato defects were classified as internal and external defects. External defects, including green epidermis, secondary growth, deformities, crackle, dry rot or decay, disease spots, mechanical damage, wormhole, rat bites and so on, can be observed from the surface. Defects affect the quality of products and increase the complexity of potato processing and raw materials loss in the potato processing.

Through observation and analysis of the potato color image, the color character between the high-quality potato and the detect one is obvious different. Good potato was light yellow, while dry rot and decay was grey or black grey, green epidermis was green or celadon. So it was suggested that these color characteristics could be considered as the recognition features of defects. In the paper, defects region color features which were extracted from color image according to the different color information of the different components in HSI and RGB color model, acted as the color features of the object Segmentation.

\subsection{Color Model}

The color is as to geometirc characteristic of the picture, have certain stability, to scale, translation, rotate, have a strong one stupid and getting wonderful quite(Wu Funing et al.,2005). Because the color information is the inherent character of the object, color characteristics is a simple and effective feature. Commonly, the format of images taken by a digital camera is in the RGB color space. RGB is the acronym of red, green, and blue. Apart from the RGB color space, the HSI color space is also close to how humans perceive colors(Deng-Fong Lin et al.,2005). HSI is the short form for hue, saturation, and intensity, respectively(Rafael C.Gonzalez et al.,2005). In this study, image color feature extraction of potatoes samples are investigated both in the RGB and HSI color space.

\subsection{Color Statistical Information}

According to the color histogram of 100 potato images, the distribution range of six color parameters were calculated. Took the good potato and dry rot ones for examples, the distribution state was shown as table 1. Except saturations had no obvious difference, others were in different range or had significant difference between the good and detect potatoes. 
Studyed on the Externaldefects Segmentation Based on the Color

Character of Potatoes

Table 1 Color Statistical Information of potatoes

\begin{tabular}{ccccccc}
\hline & Red & Green & Blue & hue & saturation & intensity \\
\hline Good potatoes & $150 \sim 255$ & $150 \sim 255$ & $90 \sim 255$ & $0 \sim 180$ & $0 \sim 75$ & $0.5 \sim 1$ \\
Dry rot potatoes & $50 \sim 150$ & $40 \sim 150$ & $45 \sim 160$ & $0 \sim 360$ & $0 \sim 102$ & $0.2 \sim 0.5$ \\
\hline
\end{tabular}

\subsection{Defects Segmentation}

For a detects potato image, scanning from left to right and from top to bottom, meanwhile calculating each pixel of the R, G, B, H, S, I value. When the parameters values were between the scope of defect range, set the RGB value of the pixel to $\operatorname{RGB}(255,0,0)$, otherwise value remained constant. As Figure 3 shows that after segmentation, background was black, defects were red, and the color of good parts did not change.
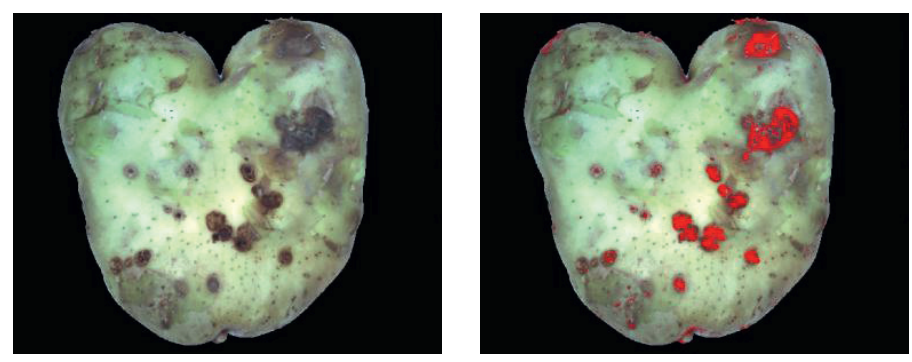

Fig3 External defects segmentation

\section{CONCLUSION}

According to the color characteristics of potato image, the background was effectively wiped off and the external detects segmentation was realized. This method was simple and effective. To find the appropriate color characteristics was the key.

\section{ACKNOWLEDGEMENTS}

The first author is grateful to the College of Electrical and Mechanical Engineering for providing her with pursuing a $\mathrm{PhD}$ degree at the Inner Mogolia Agriculture University. (Hu Zhiquan et al.,2005) 


\section{REFERENCES}

Dah-Jye Lee, James K. Archibald, Yu-Chou Chang and Christopher R. Greco, Robust color space conversion and color distribution analysis techniques for date maturity evaluation. Journal of Food Engineering, Volume 88, Issue 3, October 2008, Pages 364-372

Deng-Fong Lin, Huan-Lin Luo, Fading and color changes in colored asphalt quantified by the image analysis method.Construction and Building Materials, Volume 18, Issue 4, May 2004, Pages 255-261

Rafael C.Gonzalez,Richard E.Woods, Digital Image Processing Second Edition. Electronic Industry Press of China, 2003

Wu Funing,Yang Zibiao,Zhu Hong,etc.Applied researchers of classifying and identifying crop image.Review of China agricultural science and technology, Volume 5,2003,76 80

Ying Yibiin,Rao Xiuqin,Zhao Yun,Jiang Yiyuan.Application of machine vision technique to quality automatic identification of agricultural products. Transactions of the CSAE, January 2000, 103 108 